Brit. Y. industr. Med., 1966, 23, I.

\title{
Farm Safety
}

\author{
G. S. WILSON
}

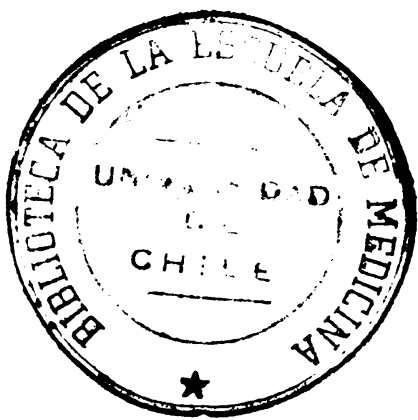

From the Ministry of Agriculture, Fisheries and Food, London

Accident and safety are related terms; the higher the accident rate in any industry, the greater is the need for safety measures designed to prevent accidents. This article discusses the accident and safety problems in agriculture, which includes horticulture and forestry.

There is still a tendency among townspeople to think of the countryside as peaceful and tranquil, a place where nothing happens very quickly and far removed from violent death or crippling injury. This pleasant rustic picture has undergone a striking change in the last 30 years owing to considerable agricultural mechanization and the development of chemical pesticides, which have brought new dangers to those who live and work on the land.

Although men have readily adapted themselves to new machines and methods, they have not proved as able to recognize new dangers and learn how to guard against them. In consequence, accidents have increased to such an extent that the whole industry has realized the need for positive preventive measures.

In this country, it is generally accepted that an employer of labour has a responsibility to provide safe working conditions for those he employs. Farm safety legislation goes a little further and usually requires an employer to provide necessary safeguards, with the added requirement on a worker to make use of them.

It is a feature of accident prevention work that it never reaches a stage when it can be regarded as complete. Even when a reduction in accidents has been achieved, the effort must be sustained or the trend will be quickly reversed.

The speed and complexity of this modern age have created dangers that did not exist a hundred years ago. To cope with this situation various organizations have been set up, sometimes supported by legislation, to protect people from accidental death or serious injury. The Factories Acts are designed to prevent dangerous working conditions in industry; workers in mines and quarries have been given similar statutory protection; a lot of time and money is being spent on road safety; and currently attention is being focused on accidents in the home. Farm safety is a comparative newcomer in this field and, like all other forms of accident prevention, it has come about because changes in the farming way of life made it necessary. Nevertheless, the short history of farm safety is an interesting study, and its future potential in this ever-changing industry promises to yield exciting possibilities.

Towards the end of the last century, it might fairly be said that farming was a reasonably safe occupation and accidents involving animals were more frequent than any other kind. The horse was

Received for publication August 21, 1965. the source of power, and only two types of machine were sufficiently dangerous to call for safety action. These were the thresher and the chaff-cutting machine; the former was dangerous because of the swiftly revolving power-driven drum into which produce was manually fed, and the latter because there was a risk of the operator's hand or arm being drawn between the rollers and on to the knives. The obvious danger that these machines presented to the operator led to the first safety legislation known to agriculture. In 1878, The Threshing Machines Act $^{1}$ was passed, and in 1897 The Chaff-cutting Machines (Accidents) Act $^{2}$ was passed. Neither Act proved particularly effective, and there is little evidence to show that serious attempts were made to enforce them. To some extent this may be due to the vague wording used to express their requirements; in both Acts we find this sort of phrase following a requirement to guard or fence, 'so far as is reasonably practicable and consistent with the due and efficient working of the machine'. Nevertheless, this seemed to be all that was necessary, and farming went on its way with little change in the traditional methods of sowing, harvesting, and the handling of animals. There were some improve- 
ments in implements and machines, but they were limited because the horse continued to be the main source of power.

In the years leading up to the second world war, there were two revolutionary and far-reaching changes bringing with them new unknown dangers never before experienced in our oldest industry. The agricultural tractor replaced the horse, making far greater power available to operate complex farm machinery, and chemical pesticides were introduced to control weeds, harmful insects, and other pests. It was because machinery and chemicals were so rapidly developed and because they introduced new hazards that protective measures became necessary on a national scale.

\section{The Gowers Committee}

Except for the somewhat ineffectual legislation already referred to, the movement to promote farm safety began in 1946 when the government of the time set up a committee to enquire into matters of 'Health, Welfare and Safety in Non-Industrial Employment'. It is generally referred to as the 'Gowers Committee' after its chairman, Sir Ernest Gowers. The enquiry was by no means restricted to agriculture but ranged over a much wider field including shops, offices, hotels and catering, entertainment, rail and road transport, fishing, shipping, and domestic employment. The Trades Union Congress and the National Union of Agricultural Workers both passed resolutions in favour of applying the Factories Acts to agriculture. The Committee noted that a lot of the machinery in use on farms only operated when it was in movement over the ground, and for this reason it was not machinery of a kind to which the Factories Acts were designed to apply. Members concluded that farm work was so completely different from work in a factory that safety precautions for agricultural workers needed further separate consideration. Few reliable statistics were available in 1946, but the War Agricultural Committees supplied information showing that with their labour force of 40,000 , accidents with machinery resulting in compensation claims amounted to 19 per 1,000 workers per year. The National Union of Agricultural Workers in evidence said that the previous five years had revealed an accident rate of $4 \%$ compared with $2 \frac{1}{2} \%$ before the war.

The Committee went on to consider the situation on farms relating to sanitary and washing facilities and found that both left much to be desired. They discussed machinery and decided that where guarding was possible it ought to be provided. It was considered that attention should be paid to lighting in farm buildings and that it should be compulsory on any holding where workers were employed to supply and maintain a suitably equipped first-aid box or cabinet. Finally, it was agreed that Ministers ought to be given powers to require the supply and use of protective clothing where workers have to handle dangerous fertilizers and chemicals.

The Committee's Report was presented to parliament in March $1949^{3}$ and the small section devoted to agriculture contained the following recommendations.

Legislation should provide for:-

(I) powers to be given to local sanitary authorities to decide the nature and extent of the sanitary accommodation to be provided on agricultural holdings where a need for special facilities exists;

(2) the supply of clean water, soap, and towels for the use of employees;

(3) the repeal of the Threshing Machines Act, I878, and the Chaff-cutting Machines (Accidents) Act, 1897;

(4) the granting of powers to the Minister of Agriculture and the Secretary of State for Scotland to prescribe by regulations $(a)$ the machines for which satisfactory guards have been devised and which are so dangerous that they should not be operated without them, and (b) the provision of protective clothing by the employer for employees using fertilizers, sprays, chemicals, and other dangerous substances;

(5) the supply and maintenance on all agricultural holdings of suitably equipped first-aid boxes or cabinets.

The work of the Committee, culminating in their report to parliament, is of historical importance in that it marks the first real attempt to prevent farm accidents. It may be said to be the beginning of farm safety.

\section{Poisonous Substances}

Dangers from the use of chemical pesticides were the most urgent problem. Their use was rapidly increasing, and many new compounds were finding their way on to farms without the careful examination and scrutiny of data that takes place today. Farmers and workers were handling poisonous substances with little knowledge of the dangers to which they were exposed, and matters came to a head in the late I940s when eight workers died from poisoning after using dinitro sprays.

Zuckerman Working Party The consequences of the increased use of toxic chemicals in agriculture were studied in more detail by a working party under the chairmanship of Professor (now Sir 
Solly) Zuckerman which reported in 1951, 1953, and 1955. The report dealt with the safety of workers handling toxic or harmful chemicals (First Report), ${ }^{4}$ with possible risks to consumers of treated crops (Second Report) ${ }^{5}$ and with possible risks to natural flora and fauna in the countryside (Third Report). ${ }^{6}$ Their main recommendations were put into effect by legislation and by the creation of a voluntary notification scheme, now known as the Pesticides Safety Precautions Scheme.

The Agriculture (Poisonous Substances) Regulations The Agriculture (Poisonous Substances) Act $^{7}$ was passed in 1952 . Regulations made under the $\mathrm{Act}^{8}$ require workers to wear protective clothing when using various specified chemicals. These are divided into four groups. The protective clothing prescribed for each group of chemicals differs according to their toxic properties and manner of use. For example, when any substance specified in the regulations is sprayed in a greenhouse from an aerosol dispenser, more items of protective clothing must be worn (overall, hood, rubber gloves, and respirator) than when mixing or diluting a substance like demeton-methyl for which operation only rubber gloves and a face shield are required. The regulations also set out detailed requirements in such matters as personal hygiene, washing of clothing, keeping of records, hours of work on scheduled operations, and notification of sickness.

Since the regulations came into force only one agricultural worker has died as a result of accidental contact with a specified substance: this occurred in 1955. He had been using ethyl mercury phosphate in a greenhouse. This chemical was subsequently withdrawn from sale to farmers and growers. Last year (1964), the Ministry received and investigated I6 reports of illness or injury among workers which had been thought to arise from contact with agricultural chemicals. These included three cases of eye injury from splashes, none of which caused permanent damage, and two cases of dermatitis ascribed to allergies. There were i I cases of illness, all of short duration; two appeared to have been due to contact with a specified chemical, but in none of the remaining nine cases was there firm evidence that chemicals were to blame.

The Pesticides Safety Precautions Scheme The Government exercises control over the introduction of new pesticides for use in agriculture, horticulture (including home gardens), and food storage through the voluntary Pesticides Safety Precautions Scheme. Under this scheme, manufacturers notify the Ministry before marketing any new chemical or recommending a new use of an existing one. They provide extensive data, including details of the physical, chemical, and biological properties of the compound, the products into which it may break down, and its mode of action. Details of experimental work on its toxicity to mammals and, where available, to man are called for as well as information on its likely effects on wild life. Its proposed use and method of application must be given, together with information about risks arising from its use. Methods of analysis, medical data, and any information about its use in other countries are also required.

Where appropriate, the Government's Advisory Committee on Pesticides and Other Toxic Chemicals (the Cook Committee) and its Scientific SubCommittee consider these data and all other information. If the committees consider it necessary they ask the manufacturer to carry out further tests. When they are satisfied that safeguards to protect the user of the chemical, the general public, animals, and wild life generally are adequate and practicable, the Advisory Committee makes recommendations for the safe use of the chemical. If this Ministry and the Ministry of Health (and the corresponding departments for Scotland) accept them, this Ministry disseminates these safety recommendations widely. It is a condition of clearance that the manufacturer must include the recommended conditions of use and safety precautions on the label. The Advisory Committee also advises the Ministry whether or not a chemical should be added to the list of chemicals specified in the Poisonous Substances Regulations.

Veterinary Products Safety Precautions Scheme In recent years a Veterinary Products Safety Precautions Scheme has been set up. This operates broadly on the lines of the Pesticides Safety Precautions Scheme and covers veterinary products on sale direct to farmers. The Advisory Committee receives scientific advice about these products from a Veterinary Sub-Committee.

Review of the Persistent Organochlorine Pesticides In view of public disquiet about the possible effects of the persistent organochlorine pesticides on human and animal life, the Minister asked the Cook Committee (then known as the Advisory Committee on Poisonous Substances used in Agriculture and Food Storage), in June 1963, to review the risks arising from the use of these pesticides in agriculture, including gardens and food storage, and to make recommendations.

The Committee presented its report in February 1964. ${ }^{9}$ It dealt mainly with five pesticides, namely, 
aldrin, dieldrin, heptachlor, DDT, and BHC. There follows a brief summary of its main findings, which relate only to the situation in Great Britain.

(I) The Committee found no evidence of any serious immediate hazards to human beings from the use of persistent organochlorine pesticides. In particular, the Committee rejected the suggestion that these chemicals might be severe liver poisons or that they could be condemned as presenting a carcinogenic hazard to man.

(2) There was circumstantial evidence for the view that the decline in population of certain predatory birds was attributable to the use of aldrin, dieldrin, heptachlor, and, to some extent, DDT. The Committee had received no evidence that the populations of other species had been affected by pesticides.

(3) Generally, the Committee was concerned that traces of some of the persistent organochlorine compounds were being found in so many places, such as human bodies, human food, wild birds, fish, and soil, and expressed the firm opinion that the accumulative contamination of the environment by these chemicals should be curtailed.

(4) The Committee recommended considerable restrictions on the use of aldrin and dieldrin, including a ban on their use in sheep dips, in fertilizer mixtures, and in gardens. It recommended that a number of uses of these chemicals in agriculture and food storage should be allowed to continue, subject to review in three years' time.

(5) No immediate restrictions on the use of DDT or BHC were recommended, but the use of DDT should be reviewed in three years' time.

The Government announced in March 1964 that they had decided to give effect to the Committee's recommendations through the voluntary Safety Precautions Schemes (see above). Generally, the recommended changes would take place at the end of the 1964 season, though in the case of sheep dips more time would be needed and the change would take place at the end of the following season.

In July 1964, the Committee presented a supplementary report ${ }^{10}$ dealing with five other chemicals, of relatively lesser importance in the organochlorine group, namely, endrin, endosulfan, chlordane, 'Toxaphene', and 'Rhothane'. In view of the comparatively small scale on which all these pesticides are used, the Committee did not recommend any significant curtailment of current uses, but recommended that if, in the near future, the amount of any one of these pesticides used in Great Britain showed a large increase, then it should be reviewed immediately. The Committee also recommended that current uses should be reviewed in any event in three years' time.
Industrial Uses of Organochlorine Pesticides In its report of February 1964, the Cook Committee, whose terms of reference were at that time limited to the use of chemicals in agriculture and food storage, drew attention to the use of organochlorine pesticides for industrial and domestic purposes such as timber preservation and mothproofing. The Committee recommended that the hazards arising from the use of these chemicals for such purposes, including any contribution they might make to general environmental contamination, be studied without delay.

The Government decided to extend the terms of reference of the Advisory Committee to cover these other uses of pesticides and also to enable it to report on other potentially toxic chemicals which the Government might wish from time to time to refer to the Committee. The title of the Committee was accordingly changed to The Advisory Committee on Pesticides and Other Toxic Chemicals. A survey of industrial uses is in progress. In view of the extension of the Cook Committee's responsibilities beyond those of agriculture and food storage, the Committee is now primarily responsible to the Secretary of State for Education and Science, while still available to advise other Ministers.

Review of Voluntary Safety Arrangements The Government recognized that voluntary safety arrangements were coming under increasing strain as scientific knowledge increased and more restrictions were found to be necessary. They accordingly asked the Cook Committee to consider and advise on any improvements and extensions of present safety arrangements that might be desirable to provide greater protection against the hazards arising from the use of toxic chemicals in agriculture and food storage. This enquiry is in progress.

Developments in Application Changes are constantly taking place in the formulation of chemicals and the manner of their application. Instead of the user being supplied with a concentrate in liquid or paste, some pesticides are now sold in granular form. The advantages are ease of handling and no need for the dilution of a concentrate before application. In recent years there has been a marked increase in the spraying of crops from aircraft. By this method, a much greater acreage can be treated in a given time, and it is especially useful where there is a widespread infestation, such as potato blight, which has to be dealt with promptly. Nevertheless, aerial spraying, whether done by fixed wing aircraft or helicopter, presents particular hazards. The pilot has to fly as near to the crop as possible in order that drift is reduced to the minimum so he 
needs to have had training and experience in low flying. He must take care to switch off the spray at the precise boundary of the area he is spraying to avoid contamination of nearby crops or buildings.

In a congested country such as ours, with a multitude of obstacles to low flying, the task of the pilot calls for the highest skill, experience, and concentration. Electric pylons, high trees, telephone wires, and hills are some of the obstacles to be avoided. The Ministry of Aviation and this Ministry work closely together in their efforts to make aerial spraying as safe as possible and to ensure that the more poisonous substances are not applied from the air. Even so every year one or two pilots crash their aircraft and either lose their lives or suffer serious injury.

\section{Safety, Health, and Welfare}

The Agriculture (Safety, Health, and Welfare Provisions) Act, 1956 As a result of the recommendations of the Gowers Report departments and interested organizations discussed detailed proposals for legislation for the general safety, health, and welfare of farm workers, and these were embodied in the Agriculture (Safety, Health, and Welfare Provisions) Act, 1956.1 This Act enables Ministers to make regulations to secure the safety, health, and welfare of agricultural workers and to guard against accidents to children arising out of the use of agricultural vehicles, machinery, and implements. The Act itself requires that a young person, i.e., under the age of 18 years, should not be employed as a worker in agriculture to lift, carry, or move a heavy weight which might be likely to cause him injury, and that first-aid boxes or cupboards should be provided on agricultural units where workers are employed. The Act also lays down that suitable and sufficient washing facilities must be provided for the use of workers. After consultation with all the interested organizations, it was agreed that the minimum should be clean water, soap, and clean towels. However, employers are expected to let their workers have access to piped water when it is available on the farm. Sanitary conveniences must also be provided. They must be properly maintained and kept clean. The local authorities are responsible for the enforcement of the provisions in the Act relating to sanitary conveniences.

Regulations under the Act to safeguard agricultural workers may relate to the use of any machinery or process, to the management of animals, and to securing safe work places, including safe means of access and safe ladders. Ten sets of regulations have been made so far and are referred to in the following paragraphs. ${ }^{12-21}$

Farm Accidents One of the interesting things about farm accidents is their diversity. Because of the extremely wide variety of jobs done by a farmer or farm worker the risks to which he is exposed are infinitely varied. They cover such things as the use of a wide range of field and barn machinery, the handling of animals, gunshot, strains and back injuries, falls of every kind, cuts inflicted by hand tools, electrocution, and some diseases that are peculiar to those who live and work on the land. In the Ministry's statistical analysis accidents are broken down into 40 main classes and sub-divided in 187 sub-classes.

FATAL ACCIDENTS It has been possible to keep accurate statistics since 1957 largely because the Act of 1956 requires that a coroner holding an inquest on the body of a person whose death may have been caused by an accident in the course of agricultural operations shall adjourn the inquest unless an appointed inspector of the Ministry is present to watch the proceedings. Because of this, coroners notify their intention to hold an inquest on such a person. In addition to being an aid to the keeping of statistics, this procedure enables inspectors to learn at first hand, from witnesses, about the detailed events that resulted in the death of the victim. On the other hand, many coroners use the attending safety inspector to give expert technical opinions on machinery or other equipment involved.

Statistics kept since 1957 reveal that nearly one third of fatal accidents in agriculture are caused by overturning tractors (Figs. I and 2). Table I shows the size of the problem and the part played by the overturning tractor.

The total accident figures include children of all ages. Since July I, 1958 regulations have prohibited children under 13 from driving or riding on

TABLE I

Fatal Accidents in Agriculture (1957-64): All Causes AND OVERTURNING TRACTORS

\begin{tabular}{|c|c|c|c|c|}
\hline \multirow{2}{*}{ Year } & \multicolumn{2}{|c|}{ England and Wales } & \multicolumn{2}{|c|}{ Great Britain } \\
\hline & Total & $\begin{array}{l}\text { Overturning } \\
\text { Tractors }\end{array}$ & Total & $\begin{array}{l}\text { Overturning } \\
\text { Tractors }\end{array}$ \\
\hline 1957 & II2 & 34 & 131 & 36 \\
\hline 1958 & 109 & 33 & 137 & 40 \\
\hline 1959 & 123 & 32 & 151 & 40 \\
\hline 1960 & 109 & 26 & 125 & 31 \\
\hline 1961 & 141 & 47 & 165 & 56 \\
\hline 1962 & 127 & 47 & 156 & 50 \\
\hline 1963 & 97 & 25 & 118 & 38 \\
\hline 1964 & 106 & $3 I$ & 131 & 38 \\
\hline
\end{tabular}




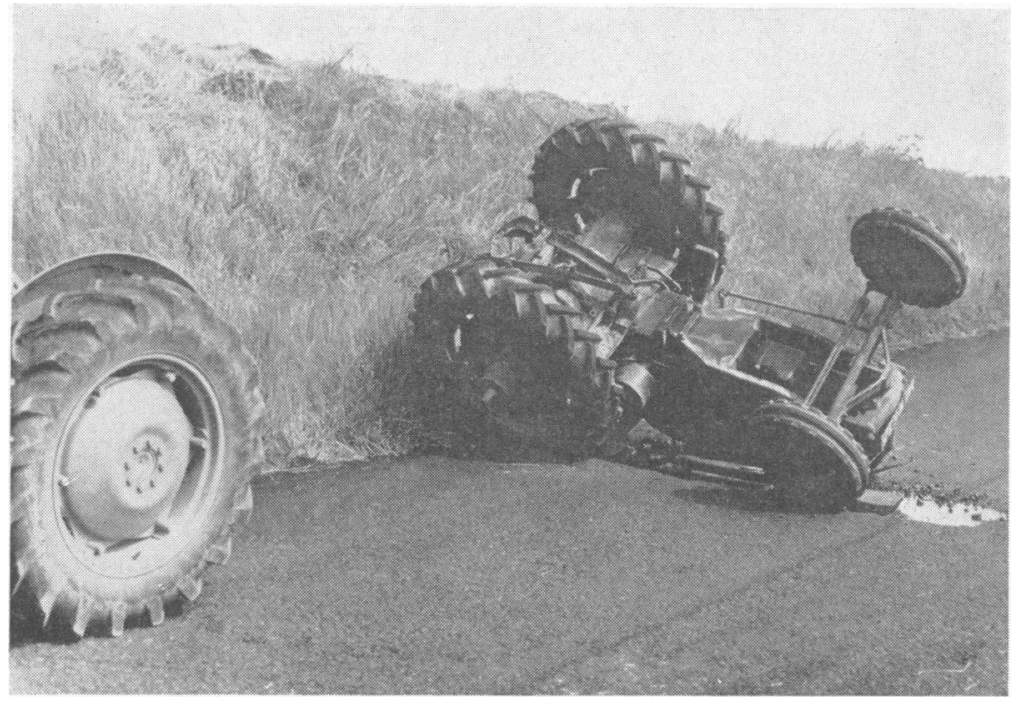

FIG. I. Overturned tractor.

a tractor, so that except for the odd breach of those regulations, the overturning figures relate to farmers and farm workers.

NON-FATAL ACCIDENTS It has not been possible to obtain complete statistics of non-fatal accidents. The Ministry of Pensions and National Insurance supplies this Ministry with information about agricultural accidents and diseases for which claims are made under the Industrial Injuries Act. Accidents to self-employed people, such as the farmer himself and often members of his family, are not included in the figures, but even on this basis, reported accidents over the period 1957-64 have ranged between 12,000 and 15,000 each year.

Particulars of accidents resulting in claims for benefit are received in the Ministry and Regional Offices but not all are worthy of further investigation. Regional Safety Inspectors examine the details of each reported case and decide whether the circumstances warrant an investigation on the farm by a field officer. The decision is influenced by such factors as a possible breach of regulations, the severity of the injuries, or the unusual nature of the accident.

OVERTURNING TRACTORS The modern agricultural tractor is a safe and stable machine but it is used in many ways and in all kinds of conditions. When stationary, it drives all sorts of barn machinery. It is used to transmit power to a wide variety of cultivation, sowing, and harvesting machinery and is the means by which produce is transported from one place to another. It works on hillsides, along the banks of rivers and dykes, and in forests. The Ministry issues a free leaflet called Why Tractors Overturn, which lists the dangerous situations and how to avoid them. It gives this advice:

Drive slowly over rough ground Slow down before turning Use a wide headland

Keep clear of ditches and banks Avoid steep slopes

Extend the wheels in hilly country Never hitch above drawbar level See to regular maintenance.

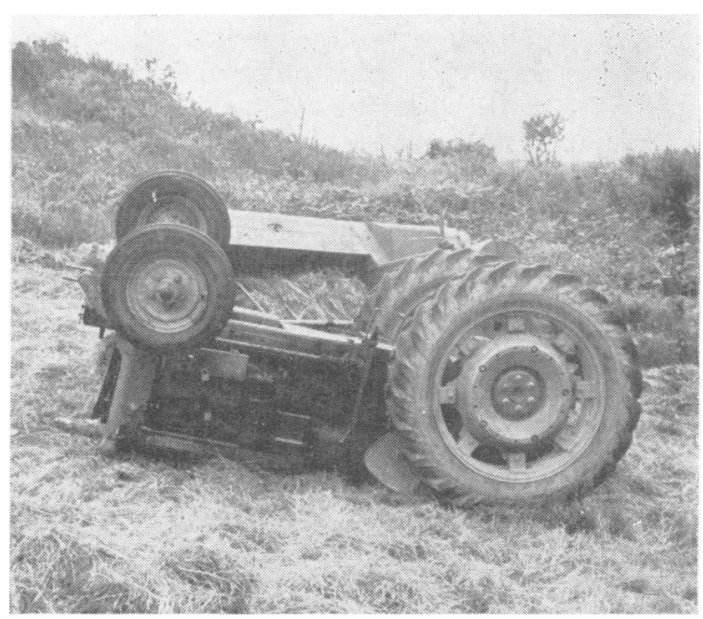

FIG. 2. Overturned tractor. 
Injuries resulting from overturning accidents include asphyxia caused by the weight of the tractor on the body, broken ribs, crushing and sometimes piercing of the trunk or head by projections such as a broken steering wheel. Even when help is at hand, the driver underneath his overturned tractor usually dies before the tractor can be moved because heavy lifting equipment has to be brought to the spot to move a tractor which weighs about two tons or more.

In an effort to cope with this major accident problem several anti-overturning devices have been tried out, but since most of them provided only limited protection they have not been widely adopted. In fact no known practical device will prevent a tractor overturning in all circumstances, so attention is now focussed on a strong cab or frame superstructure that can bear the weight of the tractor if it does overturn and so prevent the trapped driver from being crushed to death. It is essential that the cab or frame should be strong enough for this purpose, and the British Standards Institution has prepared a draft standard test. The National Institute of Agricultural Engineering has done a great deal in setting up the necessary equipment. There will shortly be issued for discussion with interested organizations proposals for regulations requiring tractors to be fitted with a safety frame or cab which has passed a standard test. Similar regulations have been in force in Sweden since 1959.

A modern tractor can transmit power from its own engine to trailed and mounted machines by means of a pulley or a device known as the 'Power Take-Off', commonly referred to as the tractor P.T.O. The P.T.O. is a splined shaft 4 or 5 inches long at the rear of the tractor, and in operation it revolves at about 540 r.p.m. The machine to be driven has a longer shaft, known as the P.T.O. shaft, which is connected to the P.T.O. of the tractor and revolves at the same speed. Should the clothing of an operator get caught up in either the P.T.O. or the shaft, it is wound round in a matter of a second or two. Fatal and very serious non-fatal accidents involving the loss of limbs have occurred. Since August 1959, regulations have required the P.T.O.14 to be shielded above and on both sides and the shaft to be enclosed. In this way the danger has been removed, and since then the only accidents that have occurred have been in circumstances where the parts were not guarded or were inadequately protected.

ANIMALS The most dangerous animal on a farm is the bull, although to a lesser extent even cows and pigs can be vicious if molested when they have young. A bull is immensely strong and quite unpredictable. There have been many instances where a bull has appeared to be quite docile for months and even years, then suddenly for no apparent reason he has turned on the stockman and mauled him with the utmost savagery. Experience shows that in general the small dairy breeds are more vicious than the larger and heavier animals.

Nevertheless, if proper precautions are taken the presence of a bull on a farm is not in itself a danger. He needs to be housed in conditions where he has light, shelter, facilities for exercise, and where he can see other animals and men as they go about. The bull pen should be so constructed that he can be fed and watered without anyone having to go inside. Means should be available for securing him so that the pen can be cleaned out. Handling equipment, e.g., a bull pole, must be strong enough for the purpose. Most accidents of this kind occur because, after a long period of good behaviour, the stockman is lulled into such a sense of security that he becomes careless in the precautions that he knows he should take. In consequence, he is totally unprepared for that sudden savage attack that so often takes place without any warning. Good housing, sound equipment, and constant vigilance are essential to prevent accidents with bulls.

Dehorning of cattle has been a feature of animal husbandry practice for some years, and at one time it seemed that this would make the bull more or less harmless. The theory was that if you take away his capacity for goring people he would have no means left to inflict serious harm on those who had to handle him and care for his necessities. To the surprise of some people, the bull changed his tactics but not his nature. He still had his enormous strength, a head as hard as iron, and his weight, and there continue to be incidents where the dehorned bull butts his victim to the ground with blows like a battering ram and then proceeds to kneel on him and at the same time deliver swinging blows with his head. The consequences may be less spectacular but the result is that the victim is either killed or suffers severe crush injuries. Dehorning is no guarantee of safety, neither is it any substitute for good housing, careful handling, and constant vigilance.

In recent years the bull population on farms has decreased as a result of artificial insemination. This has led to a reduction in bull accidents. Last year in Great Britain there were four fatal accidents and IO2 non-fatal compared with six and I4I the previous year.

Pigs do not normally attack anyone, although the odd bad-tempered boar may occasionally do so. Caution is, however, needed when entering a pen 
containing a sow with a newly-born litter. She may well attack in the supposed defence of her young. A pig has two very long tusks in the lower jaw, and the attack consists of throwing the head upwards in such a way that one of the tusks can rip the leg of an intruder. Several nasty gashes have been inflicted in this way, ripping a man's leg open, with the added risk of the wound turning septic. A light board carried by the stockman and held between the pig and his own leg gives adequate protection.

This chapter on animals might be concluded by reference to two most unusual accidents which had fatal consequences. A woman was attacked by a bantam cockerel which pecked viciously at her legs; a varicose vein was pierced and death followed. An elderly man was counting sheep as they followed each other through a gap in a hedge; four or five sheep made a rush for the gap knocking the man down. He broke his leg and died from shock.

ELECTRICITY Reference has been made to the fact that tractors are used to drive certain stationary machinery, and this often includes circular saws and grinding and crushing mills. Another very useful source of power, in the form of electricity, has proved more adaptable and convenient for use with stationary machines, and, like the tractor, the coming of electric power to the countryside has brought special dangers as well as great benefits. On the modern farm electricity is used in sheep shearing, in milking sheds, to drive mills, to supply power for the movement of grain by augers, and it has proved essential in the large grass and grain drying plants.

During the last three years 23 people have been electrocuted on the farms of Great Britain. Very few farmers or farm workers are skilled electricians, but most of them of necessity are skilled 'do-ityourself' experts in many other ways. Most of the fatal accidents are caused by people who are not electricians installing wiring, making extensions to an existing system, and failing to ensure regular inspection and maintenance by a qualified person. This latter is becoming more and more important as new uses for electric power are developed.

In damp conditions, such as are found in cowhouses, dairies or glasshouses, there is a particular risk of electric faults and corrosion of the wiring. Many electrocution deaths in agriculture and elsewhere are due to earth connexions being faulty or missing. The metal cases or framework of all electric motors, tools, and appliances and metal reflectors on infrared lamps must be properly earthed to ensure safety in handling. Earth wires are frequently of uncovered stranded copper which corrode quickly under farm conditions where contact may be made with manure or artificial fertilizers. It is most dangerous to have any portable tool or appliance connected to a lamp-holder or two-pin plug because neither of them has provision for an earth connexion. Quite often, in reports of electrocution, it has been revealed that either the victim or someone else has felt mild electric shocks but has kept the particular equipment in use until the worst has happened. It is time to get a qualified electrician in to make a thorough check on the equipment when the first shock is felt because it means that there is a fault.

The advent of electric power has meant the erection of poles carrying overhead lines and passing over farmyards and fields. They look harmless enough, but ricks must be sited well out of the way and ladders, elevators, and other high equipment must not be used in close proximity.

It is essential in the interests of the safety of men and animals that electric fences operated from a mains supply should be installed by a qualified electrician. There is a popular idea abroad that a person cannot be electrocuted if he is wearing rubber boots; this has proved to be a fatal mistake in a few cases. Although the insulating effect of rubber has doubtless saved some lives, it does not in all circumstances give complete protection against electric shock.

There are good reasons to expect that the use of electric power in farming operations will continue to expand and that such accidents will increase in number unless those who work on the land realize that here is something of which it may be said 'a little learning is a dang'rous thing'.

FALLS More people are injured in agriculture as a result of falls of one kind and another than from any other single cause. This appears to be due in part to slippery ground conditions and in part to the frequent use of ladders and stairways in the course of farm work. In Great Britain during the last four years, fatal accidents due to falling have averaged 14 per year or nearly $10 \%$ of the total. It has been noticed that elderly people tend to be more seriously affected by falling from a height; for instance, a fall from a load of bales, that would result in nothing more than a shaking for a young man, has far more serious, if not fatal, consequences to a person in the 60 or 70 age-group. Naturally most of the injuries from this cause are not fatal, but in many cases they result in serious and prolonged absence from work. The size of the problem can be seen in Table II which shows accidents reported over the last four years.

Falls account for a considerable proportion of accidents and the circumstances in which they occur 
TABLE II

Non-fatal Accidents, All Causes and those due to Falls (1961-64)

\begin{tabular}{ccl} 
Year & Total Non-fatal Accidents & Falls \\
\hline 1961 & 13,374 & 2763 \\
1962 & 14,071 & 3025 \\
1963 & 15,020 & 3690 \\
1964 & 13,730 & 3047
\end{tabular}

are many and diverse. This is clearly shown by the statistical breakdown of this general category into the following subclasses:

\section{Falls (general)}

By breakage of ladder

From loose ladder or stepladder, stairway or steps

From loading bays and doors

From ricks and stacks

From vehicles and trailers

From other heights

Through floors and openings

Carrying or moving weights

Into cavity

On level, unburdened

Other.

Even with this fairly comprehensive sub-division, the numbers appearing in the class of 'other' falls are by far the greatest, indicating that a more detailed breakdown would reveal even more diverse circumstances.

Obviously it is impracticable to make safety regulations that will wholly prevent people from falling and hurting themselves, but a study of the problem some years ago showed that some protection could and should be given. It was found that many ladders in use on farms were ill-constructed, badly maintained, and unsuitable for the manner of their use. In consequence, a number of accidents occurred due to stiles and rungs breaking when someone was ascending or coming down. Regulations relating to ladders, made in $1957^{13}$, require employers to provide ladders that are properly constructed, well maintained, and safe for a worker to use. Responsibility was placed on workers to report any defects, such as missing rungs and cracked or broken stiles, and to ensure that a ladder was equally supported on each stile and securely placed in position before use. Similarly, in 1959 regulations were made requiring certain safety standards in farm buildings. ${ }^{17}$ These included handrails on stairways, and handholds or guardrails for apertures where there was a drop of more than five feet. Again responsibility was placed on an employer to provide for the safe means of working in farm buildings and also on the worker to make use of the safety devices and report any defects that might occur in use.

A good many falls occur when sacks or bales are being carried down steps or across an uneven farmyard. These are not necessarily related to the weight being carried. Bulk is another factor which may interfere with visibility so that a step on a stairway cannot be seen or some obstruction avoided. Nevertheless, it was considered that some restriction should be placed on the weight which a worker in agriculture should be required to lift or carry where this was possible. From July I, 1965 it has been an offence to require a worker to lift or carry unaided a sack or bag which together with the contents weighs more than $180 \mathrm{lb}$. ( $81.5 \mathrm{~kg}$.).

The Field Machinery Regulations ${ }^{21}$ require proper mounting steps for tractors, con'sine harvesters, and other mobile machines to facilitate mounting and dismounting. They also require toeboards and guardrails on field machinery where workers have to stand to perform any operation. The dangerous practice of riding on a drawbar of a machine that is towing or being towed is prohibited, and it is forbidden to dismount from a moving machine except in an emergency.

Although these statutory measures must reduce the number of injuries sustained in fall, a considerable problem still remains which can only be solved by education and the application of commonsense under working conditions.

There can be no doubt that caref 1 attention to footwear would prevent a number of falls from stairways, from machines and vehicles, and even on a level surface in slippery conditions. Rubber boots are very popular because they are waterproof, but when the tread has worn smooth they are apt to cause a slip and a nasty fall. It is likely that the British Standards Institution will be giving attention to this question of safe non-slip footwear for agriculture.

CIRCULAR SAWS Under both factory and farm safety acts a circular saw has to be fitted with suitable guards. In agriculture such a saw must have that part of the blade below the bench guarded on both sides, there must be a top guard extending over the top of the blade following the curve to a point directly over where the cutting edge goes through the table. At the rear there must be a riving knife to keep the cut open when rip sawing so that the timber does not bind on the blade, and there must be available to the operator means by which the power can quickly be disconnected. An employer must not permit a worker to use the saw if the blade is cracked, if it has been repaired by 
brazing or welding, or if it has two or more teeth missing. The point about brazing or welding is very important because the delicate temper of the blade can be changed so that it may disintegrate when brought into use.

Most farmers are aware that a circular saw is a very dangerous piece of equipment and they make sure that it is guarded to comply with regulation requirements. But the difficulty is that, even so, a part of the blade must be left exposed to perform the job for which it is intended and this inevitably leads to numerous accidents. Much of this work consists of sawing tree trunks and branches into logs for firewood and, because it is intermittent, few farm operators ever have sufficient experience to become efficient sawyers. Every year there are between 100 and 150 accidents with circular saws, and in most of them one or more fingers are cut off. This is a serious injury for anyone engaged in farm work where both hands and all fingers are clearly needed. This again is an example where legislation can provide only partial protection, and the rest is up to the good sense, care, and attention of the operator.

Even hand-cutting tools, such as the hook, hedgebill, axe, and slasher, contribute their quota to the accident toll, for in England and Wales alone reported injuries from these and other hand-cutting tools have averaged just over 1,000 per year over the past three years. It is not possible to guard hand tools such as these, and no legislation could prevent accidents of this nature.

GUNSHOT On most farms there is a shotgun which is used for pest destruction and for sporting purposes. During the past five years 48 people have been accidentally shot dead on the farms of Great Britain. This kind of accident invariably results from either ignorance of the rules of good gun handling or carelessness on the part of someone who knows the rules. A gun is quite harmless when the cartridges have been removed, and this should always be done before sliding down a steep bank, getting over a fence or forcing a way through a hedge. Modern guns have a safety catch but too much reliance should not be placed upon it in the circumstances just described. It is fatally easy for a twig in a hedge or the spikes in a barbed wire fence to push the safety catch to the 'off' position unknown to the person carrying the gun.

In spite of repeated warnings about carrying loaded guns on tractors and farm machines this dangerous practice still continues, especially at harvest time when corn is being cut and the man on the tractor or combine might get the chance of a quick shot at a young hare or rabbit as it emerges from the standing corn. There have also been instances where someone has left a loaded gun propped up in the corner of a shed and a young boy has got hold of it with fatal consequences to himself or someone else. Accidents with guns can only be prevented by the exercise of constant care in use and by making certain that at all other times the gun is unloaded.

CHILDREN Fatal accidents to children under I5 years amounted to 16 each year from 1960 until 1964, when the number increased to 18 . This is a problem that is much more serious in agriculture than in industry generally. Children are not found in coal mines, quarries, and factories, but the children of farmers and farm workers live on the site of farming operations. The farmyard and fields are their natural playground, and, as soon as they are able, they begin to take an active interest in everything that goes on and are keen to take part. Although the law prevents them from driving or riding on tractors and other specified machines and implements, it cannot ban them from the places where such things are being operated, neither can we keep them out of farm buildings where stationary machinery is in use. The very young child who has just started to walk can be in very real danger when he crawls under a trailer or wanders in front of a tractor in a position where it cannot be seen by the driver as he starts to move off. Most of the accidents involve machinery in one way or another, and the need for prevention places a heavy responsibility on workers and parents alike.

In recent years there has been a marked increase in the number of very young children found drowned in ponds, sheep dipping tanks, and even shallow pools. In a recent message to a farming paper the Minister of Agriculture wrote 'Everyone will share my concern for the safety of children who live on farms and will be sorry to learn that last year 18 were killed which was two more than in any of the three previous years'.

\section{The Safety Inspectorate}

The Safety Act of 1956 and the Poisonous Substances Act of 1952 both empowered the appropriate Minister to appoint such inspectors as he deemed necessary to ensure that regulations were observed. Up to 1957 there was a small corps of about 30 officers whose duties included enforcement of orders made under The Agricultural Wages Act, I948 and similar duties under The Poisonous Substances Act. It was decided that this was the most suitable existing organization within the Ministry which could be expanded to take in the 
additional work of farm safety. Eventually, after a course of training, a team of about 70 officers was appointed to carry out work under the three Acts, and a valuable asset to the new inspectorate came from the recruitment of a number of machinery inspectors whose work was running down as the Ministry closed its wartime machinery services.

In 1960 , as a result of a field officer re-organization plan, the wages work was taken away and the present system was brought into being. It is necessary to explain that, for agricultural administrative purposes, England and Wales are divided into eight regions each with its own regional controller and staff. These regions are subdivided into a total of 3I divisional offices.

The new safety organization responsible for poisonous substances and farm safety work is as follows:

I. At London Headquarters there is a chief safety inspector and two deputy chief safety inspectors. Their duties are national in character and include framing regulations and general policy, consultation, and liaison with outside organizations at national level, publicity policy, and advising on parliamentary matters affecting farm safety.

2. There are eight regional safety inspectors situated at regional offices who are responsible under the regional controller for general technical supervision of the work in their respective regions. They liaise with machinery manufacturers and keep the chief inspector advised of any new hazards or technical problems as they arise. They also attend inquests on the police or coroner's notification.

3. Each of the 3I divisions has a full-time safety specialist who has technical responsibility for work in each division and maintains contact with local agricultural machinery dealers. He also deals with the more complex enquiries including cases of suspected poisoning by agricultural chemicals.

4. Also located at divisional offices there is a total of over 400 field officers who carry out farm safety inspections and related work as well as other general field officer work.

The training of these 400 field officers to the standard required was a major task which was only completed in the spring of 1965 .

All the officials mentioned have a responsibility to enforce the regulations under the two Acts, but prosecutions are not numerous, and the aim has always been to get compliance by persuasion and advice and only to resort to legal measures in extreme cases. Above all, the object is to prevent accidents, and that this is being achieved is largely due to the willing co-operation of farmers and farm workers.

\section{Diseases}

It is generally accepted that by its very nature farming is a healthy occupation in that most of the work is done in the fresh air of the countryside and includes plenty of physical exercise. Nevertheless, there are certain diseases to which the worker on the land is exposed to a greater extent than the general public; these include Weil's disease, farmers' lung, tetanus, ringworm, brucellosis, and, to a lesser extent, anthrax.

Weil's Disease In 1962 four people employed in agriculture died from Weil's disease, and almost every year two or three people die from this cause. Such infection may be due to ingestion of food or water contaminated by the urine of infested rats (usually, in this country, of the species Mus norvegicus or brown rat); alternatively, the infection may enter through the skin or the mucous membranes of the eyes, nose, or mouth.

In a survey carried out some years ago, a large number of rats was caught and examined; it was found that $40 \%$ were infected. The Leptospira live in the rat's kidneys, apparently harmless to the rat itself, where they multiply and are constantly excreted in the urine. For the Leptospira to remain infective they must land on water or some other damp, non-acid medium, such as mud, when they will remain active for some time. Thus the disease is contracted during exposure to damp, rat-contaminated conditions. This means that, by the nature of their work, agricultural workers, land drainage workers, miners, and sewer men are at risk. Leptospira are particularly likely to enter the body through cuts, scratches, and abrasions of the skin. The obvious answer to this unpleasant problem is the total eradication of rats, but this is easier said than done. In the meantime, protection against infection can be achieved by carefully covering all cuts and scratches on the hands and arms especially, wearing gloves when handling rats and paying meticulous attention to hand-washing before eating, drinking or smoking. Even a dead rat can infect and is preferably handled with a shovel or some other suitable tool rather than the hands.

Tetanus Tetanus is by no means confined to farmers and workers but, because the organism is present in the soil of most farms, they are at greater risk than the general population. The disease is caused by Clostridium tetani which can persist as spores in soil, manure, dust, or even hay for a long time. Among animals it attacks horses and to a lesser degree cattle, pigs, sheep, and dogs. The organism thrives best in a deep cut or puncture 
wound, which renders the land worker particularly vulnerable because of the high frequency of cuts with hand tools and the numerous accidents that occur to the hands and feet from the tines of a fork. Fortunately only a few people die from this particular cause in the industry but some concern arose in I96I when five people died. In some parts of the country coroners and others were inclined to advocate wholesale anti-tetanus immunization of farm workers. Nothing came of these suggestions and the problem remains.

Farmer's Lung In June 1965, the Minister of Pensions and National Insurance, in reply to a written question in the House, said: 'I have recently received the further advice $\mathrm{cf}$ the Industrial Injuries Advisory Council on the wording of the occupational cover for farmer's lung. The Council considers that the cover which it originally recommended in its report on farmer's lung (Cmnd 2403)22 should be defined with a greater degree of precision. I have accepted the Council's advice, and I have decided that farmer's lung should be prescribed in relation to any occupation involving exposure to the dust of mouldy hay or other mouldy vegetable produce by reason of employment (a) in agriculture, horticulture, or forestry; or $(b)$ in loading or unloading or handling in storage such hay or other vegetable produce; or $(c)$ in handling bagasse. Both the Council and $I$ are satisfied that this cover is sufficiently comprehensive in the present state of knowledge about the disease.' The National Insurance (Industrial Injuries) (Prescribed Diseases) Amendment Regulations $1965^{23}$ prescribing farmer's lung came into operation the same month.

After a wet summer, the chances of contracting farmer's lung increase because hay and corn may be harvested damp, and when it is put into stacks, either in bales or loose, the growth of microorganisms causes heating. The moulds believed to be responsible for farmer's lung are among those which grow well in the overheated hay. Their spores therefore may be expected to be present in mouldy hay or corn which has been over-heated. When the produce is disturbed, for example, for threshing corn or feeding hay to cattle, the dust containing the spores can be inhaled. Inhalation of these spores by susceptible individuals may then cause the condition known as farmer's lung.

There is every reason to believe that the wearing of a suitable mask or respirator which prevents the inhalation of the spores would reduce the incidence of the condition. Advice on suitable masks and respirators can be obtained from the divisional offices of the Ministry of Agriculture, Fisheries and
Food or from the Department of Agriculture and Fisheries for Scotland.

There is no simple way of recognizing the crop that may be potentially dangerous; and anyone handling hay, corn or similar produce that has been harvested in damp conditions and stored in a way that could result in heating and drying out should take care to avoid breathing in the spores by $(a)$ keeping to windward when forking or otherwise handling sheaves of corn during threshing; and (b) taking care not to handle hay in such a way as to cause an upsurge of dust.

The problem of farmer's lung may be increased if a new method of storing grain is adopted and it seems likely that it will be. This involves storing grain with a moisture content of between $18 \%$ and $25 \%$ in sealed silos. The oxygen in the silo is soon used up and replaced by a concentration of $\mathrm{CO}_{2}$. If air is permitted to enter (and that must happen when the grain is used for cattle feed, if not before) then various moulds start to form including the spores responsible for farmer's lung. This may provide an additional hazard to the stockman and possibly to animals as well. This is a development that will have to be watched and assessed in relation to risk.

Dermatitis Loss of working time due to this skin condition is very serious in horticulture and to a lesser degree in agriculture. It occurs most often among people concerned with the following jobs: sorting and packing bulbs, particularly tulips and hyacinths; gathering, bunching or packing cut flowers such as daffodils, narcissi, tulips, and chrysanthemums; harvesting self-blanching celery; handling plants especially primula obconica, geranium, dahlia or tomato; dressing of seed and handling dressed seed.

It also occurs among people using mineral oils such as diesel fuel and similar petroleum products. Workers who use strong synthetic detergents for cleaning milking utensils in dairies have also been affected. A leaflet entitled 'Dermatitis among landworkers' has been issued, giving advice on the wearing of protective clothing and skin hygiene.

Others Those who work with cattle have always been liable to ringworm, but, largely due to much better control of ringworm in the cattle themselves, there are many fewer cases of infection than there used to be.

In spite of mechanical lifting devices, which can take care of some of the heavier jobs, there are still many jobs on all farms that entail lifting effort by the person concerned. Synovitis is still a very 
common complaint, generally due to manual lifting or manipulation of tools and implements.

Although brucellosis is found from time to time on farms, only a few cases each year are reported of its transmission to man. Even fewer are cases of anthrax because this disease is less common than it used to be among cattle.

\section{Looking Ahead}

We have seen how far-reaching changes have taken place in farming over the last three decades, resulting in great increases in production and efficiency. Today British agriculture is said to be the most highly mechanized in the world. All the time, agriculturalists, chemists, agricultural engineers, and scientists are probing into the future, a future that will see new methods replacing old ones and even greater advances in the development of machines and chemicals. Accident prevention is accepted as an essential part of this progress, and those who have responsibility for farm safety will need to be vigilant to ensure that safety standards keep step with other forms of progress. Every new development must be studied in relation to fresh risks and the protection that ought to be provided against such risks. At the same time, it may be necessary to take a second look at some existing accident problems and the ways in which they have been tackled.

Ergonomics There is an important part for ergonomics in British agriculture for some of our machinery is not well adapted for human operation. There is an equally important application to manual work which is unlikely to be replaced by machines on the smaller farms because of the capital investment involved.

Under the existing system of reporting farm accidents it is shown that well over 2,000 a year come under the heading of strains of one sort or another. Some are trivial, but others result in weeks off work and may result in permanent disability or may create a weakness which leads to further strains of greater severity. As yet, little work has been done on applying ergonomics to agriculture in this country.

The ride comfort of the farm tractor was reviewed by Mathews (1964) ${ }^{24}$ last year, and work on these problems is continuing. Equipment has been set up to measure the degree of vibrations on various parts of the driver's body transmitted from the tractor wheels and simulated in varying conditions of terrain. The ill effects of tractor driving on health were described in a classic paper by the two Roseggers in $1960^{25}$ and are the subject of study in various countries. It seems likely that the large amplitude oscillations in tractor driving sometimes damage the structure of the back, so causing a high incidence of injuries. In Germany and the United States of America studies have already been made on tractor design in relation to driver comfort.

Agricultural machinery tends to be noisy. Among the worst offenders in this respect are tractors, rotary cultivators, and chain saws. There has been no systematic study of the noise levels of agricultural machinery apart from the measurements made at the National Institute of Agricultural Engineering when tractor tests were carried out. There has also been no survey of the hearing of the agricultural population.

Other problems to be studied include the conditions under which work has to be performed in farm buildings. For example, the piggery must be warm and humid to suit the animal, so the pigman works in an atmosphere that may not be suitable for the work he has to do. Much farm work in buildings during the winter months is carried out in artificial light, sometimes badly sited and quite inadequate. In the past, insufficient thought has been given to installing machinery in relation to the needs of the operator, and many of the machines and implements towed behind a tractor require the driver to twist round in his seat to control them or make adjustments whilst still driving the tractor. There is every indication that work on the application of ergonomics to agriculture will be accelerated with a view to increasing efficiency and safety.

Machines Bigger and more powerful machinery is a clear certainty for the foreseeable future. Further efforts will be made to reduce the manpower needs of the industry. Experimental work is going on which will doubtless result in a driverless tractor before long. When this comes about a high degree of safety will have to be built into it at the design and manufacturing stage. Potato harvesting and sorting machines have always suffered from the fact that they cannot differentiate between a potato and a stone or a clod of earth of comparable size. This may be overcome in the future by the use of an $x$-ray device allowing the machine to divert the unwanted material from the crop. Here again thought will have to be given to the possibility of radiation hazards to the operators.

Whatever developments take place in the future, at least the industry is now fully alive to take accident prevention into account throughout all the stages of experiment, research, and manufacture.

Publicity In September 1956 the first three safety inspectors appointed by the Ministry of 
Agriculture met to examine the problem of accidents in agriculture. Their mandate was simply to prevent farm accidents. It soon became evident that some accidents could be prevented by making regulations requiring danger spots to be guarded and dangerous practices prohibited. This was done, but there remained a large number of accidents of a different kind-those caused by ignorance, carelessness, human error, and sometimes sheer folly. The majority of farm accidents result from these four basic causes: ignorance must be dealt with by education and the other three by using every possible means of publicity.

Fortunately, help was readily available from many sources, and interest grew as time went by. Films on the subject have proved an immensely popular way of putting over education and instruction. The following nine films were made by government departments: 'Tractor sense' (good driving practice); 'Time for thought' (gunshot, etc.); 'By your hand' (children); 'Game of chance' (falls); 'Beware of the bull'; 'Why tractors overturn'; 'Take care when you spray'; 'Safety with circular saws'; and 'Tractor follies' (P.T.O. dangers, etc.). The Norfolk Education Committee has recently made a very telling film entitled 'Hazards on the land'. Some idea of the value of these instructional films may be given when it is realized that the first two have been shown over 4,000 times each. Two more films are in the course of preparation; one will deal with correct ways of lifting and carrying, and the other with safe ways of housing and handling bulls. The British Broadcasting Corporation and the Independent Television Authority have given support making use of three television fillers as well as providing space in their regular programmes.

In 1958 the Royal Society for the Prevention of Accidents (RoSPA) appointed a full-time safety officer and formed a national committee on which all the interested organizations are represented and which includes members from Northern Ireland. A mobile caravan was purchased for the safety officer which can quickly be adapted for display purposes at agricultural shows.

RoSPA has played a leading part with the help of the National Farmers' Union and the National Union of Agricultural Workers in forming county farm safety committees. There are about 30 of these which provide an invaluable service in the study of local safety conditions and can take appropriate steps to deal with many of them. They should continue and expand their activities.

\section{International}

Although Great Britain can claim to lead the world in measures taken to prevent accidents in agriculture, many other countries are giving careful thought to their own problems in this respect and are taking steps to cope with them. International organizations are showing a keen interest in this problem. The International Labour Organization (I.L.O.) has drawn up a Convention on the guarding of all power-driven machinery including agricultural machinery.

In September 1963 a working party set up by The Council of Europe met in Strasbourg with the task of drawing up a list of jobs in agriculture that were considered dangerous for young persons, i.e., under I8 years. The working party carried out a careful study of agricultural practice in the countries represented, and, not surprisingly, found that they varied considerably. For instance, there were accident problems in the harvesting and processing of grapes in France and Italy that did not exist in the northern European countries of Belgium and Holland. Recommendations were drafted to be submitted to the governments of member countries.

In April 1964 there was a meeting in Geneva of experts on Safety, Health and Welfare in Agriculture held under the auspices of the I.L.O. As a result it has been decided to set up an international panel of consultants who will confer from time to time and study current problems in this field. A code of practice is to be published as soon as possit le which will be widely circulated to persons in many countries who hold responsibility for safety and health in agriculture. Both the I.L.O. and the Council of Europe are closely concerned with chemical pest control and have committees constantly reviewing the situation.

The International Social Security Association, a semi-autonomous body working in close relationship with the I.L.O., has a committee on the prevention of occupational risks which considers hazards in many industries including agriculture. It has been very active in collating information on the subject from both eastern and western countries.

The Organization of Economic Co-operation and Development has done a lot of work through its sub-committees on agricultural machinery and is currently engaged in trying to formulate an international standard test of tractor safety cabs which will be of great significance if this form of protection becomes widely adopted. In the Commonwealth there is growing concern over farm accidents, especially in Australia and New Zealand. A great deal of advisory safety work is going on in Australia, and New Zealand has special and serious problems on her hands since their tractor overturning deaths are nearly as numerous as our own, with a much smaller tractor population. 


\section{Conclusion}

As a movement 'Farm Safety' has a short history and, although a lot has happened during the past nine years, it is the massive task ahead that matters. In recent years accidents to those who live and work on the land have shown a downward trend, but any relaxation in effort could quickly result in that trend being reversed.

\section{REFERENCES}

${ }^{1}$ The Threshing Machines Act, 1878 .

${ }^{2}$ The Chaff-cutting Machines (Accidents) Act, I897.

${ }^{3}$ Health, Welfare and Safety in Non-Industrial Employment. Hours of Employment of Juveniles. Report by a Committee of Enquiry. Command 7664, H.M.S.O. March 1949.

${ }^{4}$ Toxic Chemicals in Agriculture. Report of the Working Party, H.M.S.O. April I95I.

${ }^{5}$ Toxic Chemicals in Agriculture. Residues in Food. Report of the Working Party, H.M.S.O. October 1953.

${ }^{6}$ Toxic Chemicals in Agriculture. Risks to Wild Life. Report of the Working Party, H.M.S.O. June I955.

${ }^{7}$ The Agriculture (Poisonous Substances) Act, I952.

${ }^{8}$ The Agriculture (Poisonous Substances) Regulations 1963-65. (S.I. 1963 , No. 845 ; S.I. 1964 No. 663 ; S.I. 1965 No. 76 ; S.I. 1965 No. 568 .)

${ }^{9}$ Review of the Persistent Organochlorine Pesticides. Report by the Advisory Committee on Poisonous Substances Used in Agriculture and Food Storage. H.M.S.O. February 1964 .
${ }^{10}$ Review of the Persistent Organochlorine Pesticides, Supplementary Report by the Advisory Committee on Pesticides and other Toxic Chemicals. H.M.S.O. July 1964.

${ }^{11}$ The Agriculture (Safety, Health and Welfare Provisions) Act, 1956.

${ }^{12}$ The Agriculture (First Aid) Regulations 1957 (S.I. 1957 No. 940).

${ }^{13}$ The Agriculture (Ladders) Regulations 1957 (S.I. 1957 No. 1385).

${ }^{14}$ The Agriculture (Power Take-off) Regulations 1957 (S.I. I957 No. 1386).

${ }^{15}$ The Agriculture (Avoidance of Accidents to Children) Regulations 1958 (S.I. 1958 No. 366).

${ }^{16}$ The Agriculture (Circular Saws) Regulations 1959 (S.I. I959 No. 427).

${ }^{17}$ The Agriculture (Safeguarding of Workplaces) Regulations 1959 (S.I. 1959 No. 428).

${ }^{18}$ The Agriculture (Stationary Machinery) Regulations I959 (S.I. 1959 No. 1216).

${ }^{19}$ The Agriculture (Lifting of Heavy Weights) Regulations I959 (S.I. 1959 No. 2120).

${ }^{20}$ The Agriculture (Threshers and Balers) Regulations I 960 (S.I. I 960 No. II99).

${ }^{21}$ The Agriculture (Field Machinery) Regulations 1962 (S.I. 1962 No. 1472).

${ }^{22}$ Notes on Diagnosis of Occupational Diseases prescribed under the National Insurance (Industrial Injuries) Act, I946. H.M.S.O. 1950. Farmers' Lung-Report by the Industrial Injuries Advisory Council. Cmnd. 2403, H.M.S.O. July I964.

${ }^{23}$ The National Insurance (Industrial Injuries) (Prescribed Diseases) Amendment Regulations 1965-(S.I. 1965 No. II8).

${ }^{24}$ Mathews, J. (1964). F. agric. Engng Res., 9, 2.

${ }^{25}$ Rosegger, R., and Rosegger, S. (I960). Ibid., 5, 24 I. 